\title{
Management of plantar fasciitis in the outpatient setting
}

Ang Tee $\underline{L i m}^{1}$, MspMed, MMed, Choon How $\underline{H o w}^{2}$, MMed, FCFP, Benedict $\underline{T a n}^{1}$, MSpMed, FAMs

\begin{abstract}
Albert limped into your consultation room complaining about the right foot pain he had been having for the past three weeks, which was especially excruciating upon his first few steps from his bed. He related that the pain began a week after he started preparing for a half marathon as part of his company's 'Get healthy' pledge. He had joined the running interest group in their daily long runs, but dropped out after only one week due to the right foot pain and occasional painful cramps in his calf muscles at night. Although Albert has taken diclofenac tablets daily over the past week, the pain has persisted.
\end{abstract}

\section{WHAT IS PLANTAR FASCIITIS?}

Plantar fasciitis is the most common cause of plantar heel pain, with an incidence of one million patient visits per year in the United States of America. ${ }^{(1)}$ Even so, the exact histopathology of plantar fasciitis is not fully understood. It is currently thought to be secondary to myxoid degeneration, microtears within the plantar fascia, collagen necrosis and angiofibroblastic hyperplasia of the plantar aponeurosis, and not due to an inflammatory process. ${ }^{(2)}$

\section{Presentation}

The patient usually presents with gradual onset of pain over the medial side of the plantar heel that is most noticeable when taking the first few steps in the morning. The pain may get better after a short period of walking, but returns when performing activities that involve prolonged weight-bearing, such as standing, walking or running. The patient may also complain that heel pain worsens after repeat weight-bearing following a period of rest, such as standing after a period of sitting at a desk.

\section{Risk factors}

The plantar fascia runs from the calcaneus to the toes; most of the load falls on its medial edge, from the medial calcaneal process to the first toe. As the plantar fascia helps to hold up the medial arch of the foot, any load on the medial arch (e.g. on weight-bearing) stretches the plantar fascia. Most lesions occur at the origin of the fascia, the medial calcaneal process. The plantar fascia is also loaded via the windlass mechanism of the foot when the big toe is dorsiflexed, such as in forefoot running.

Any factor that mechanically loads the plantar fascia can be considered a risk factor for plantar fasciitis. Risk factors can be divided into intrinsic and extrinsic factors. Intrinsic factors relating to the patient include obesity, pes planus, pes cavus, reduced range of ankle dorsiflexion and tight calf muscles. ${ }^{(3)}$ Extrinsic factors, relating to the environment and training, include running on hard surfaces, walking barefoot, a sudden increase in running intensity and/or volume, and prolonged walking/standing. ${ }^{(3)}$

\section{WHAT CAN I DO IN MY PRACTICE? Imaging}

Radiography has limited value in the diagnosis of plantar fasciitis. However, a lateral weight-bearing view of the foot may be helpful in excluding differentials such as acute calcaneal fracture, or Sever's disease (calcaneal apophysitis) in younger patients. 50\% of patients with plantar heel pain may have heel spurs, but the relationship to subcalcaneal pain has not been established. ${ }^{(4,5)}$ Heel spurs are now thought to be a result of traction forces on the plantar fascia origin rather than the cause of plantar fasciitis.

Musculoskeletal ultrasonography is a very useful and reliable tool in diagnosing plantar fasciitis, as it is a well-tolerated, noninvasive imaging modality with no ionising radiation. According to published normative values, plantar fascia thickness in asymptomatic healthy adults ranges from $3.3 \pm 0.3 \mathrm{~mm}$ to $3.9 \pm 0.5 \mathrm{~mm}$; a thickness greater than $4.0 \mathrm{~mm}$ is considered abnormal. ${ }^{(6-10)}$ Apart from quantifying and thereby monitoring the severity of the plantar fasciitis, ultrasonography can conclusively exclude a differential diagnosis such as plantar fascia fibromatosis, which appears as a fusiform swelling distal to the plantar fascia origin, and heel pad contusions, which are superficial to the plantar fascia.

\section{Treatment}

Treatment is largely nonoperative, with $90 \%-95 \%$ of patients experiencing resolution of symptoms within 12-18 months.

\section{Activity modification}

Modification of activities should be advised, while those that involve repetitive impact, such as running (even on a treadmill), should be avoided during the treatment phase. Patients can continue performing non-weight-bearing activities such as cycling, swimming and rowing to maintain their cardiovascular fitness while minimising cyclic loading. A gradual return to activity may be allowed after the patient is asymptomatic for $4-6$ weeks and no longer has localised tenderness over the plantar fascia. 


\section{Plantar fascia stretch and ice massage}

Plantar fascia and calf stretches are inexpensive and easy to learn. The plantar fascia-specific stretch has been shown to be more efficacious than the isolated Achilles stretching programme. ${ }^{(11)}$ The plantar fascia-specific stretch is performed by dorsiflexing the toes with one hand (taking advantage of the windlass mechanism) and palpating the plantar fascia with the other hand to ensure that it is taut (Fig. 1a). The stretch is held for a count of 30 seconds and repeated at least three times in each session. This should be done daily, especially before taking the first step in the morning and before standing following a period of prolonged sitting. Ice massage can also help to reduce plantar fascia pain. One method involves rolling a frozen can under the foot with moderate pressure for five to ten minutes at the end of each day (Fig. 1b).

\section{Night splints}

The use of night dorsiflexion splints can also help with plantar fasciitis, especially pain that is worse during the first few steps in the morning. Night splints have produced highly positive outcomes such as resolution of symptoms within 12 weeks of use. The patient may see improvement as early as after four weeks of use. ${ }^{(12)}$

\section{Orthotics}

To reduce loading of the plantar fascia on weight-bearing, orthotics should help to hold up the medial arch of the foot without placing any direct pressure on the plantar fascia. Additionally, to reduce the direct pressure of the ground on plantar fascia swelling, an aperture can be incorporated into the orthotic such that the swelling sits in the aperture. For athletic individuals, semi-rigid orthotics are the most practical solution, and it is helpful for physicians to specify 'semi-rigid orthotics with plantar fascia accommodation and aperture' when prescribing orthotics to be fabricated by a podiatrist. The use of orthotics, including heel cups and plantar fascia support insoles, was found to be effective in alleviating pain from plantar fasciitis. In addition, it was shown that prefabricated insoles were not inferior to custom-made ones, giving patients without true biomechanical abnormalities, such as pes planus/cavus, a more economical option. ${ }^{(13,14)}$ However, as prefabricated insoles come in a myriad of designs, physicians should exercise caution when making generalisations.

\section{Analgesia}

The use of nonsteroidal anti-inflammatory drugs (NSAIDs) to treat plantar fasciitis is a widespread practice that has been called into question, as plantar fasciitis is not an inflammatory process. This is supported by a recent study showing no significant difference in pain and disability scores in patients who were given NSAIDs compared to those who received a placebo. ${ }^{(15)}$ However, when combined with other treatment modalities, NSAIDs or simple analgesics may help to provide short-term pain relief. ${ }^{(14)}$

\section{Steroid injection}

Localised steroid injections into the plantar fascia have been shown to provide effective short-term relief of plantar fascia pain for up to three months. ${ }^{(16)}$ There is, however, increased risk of
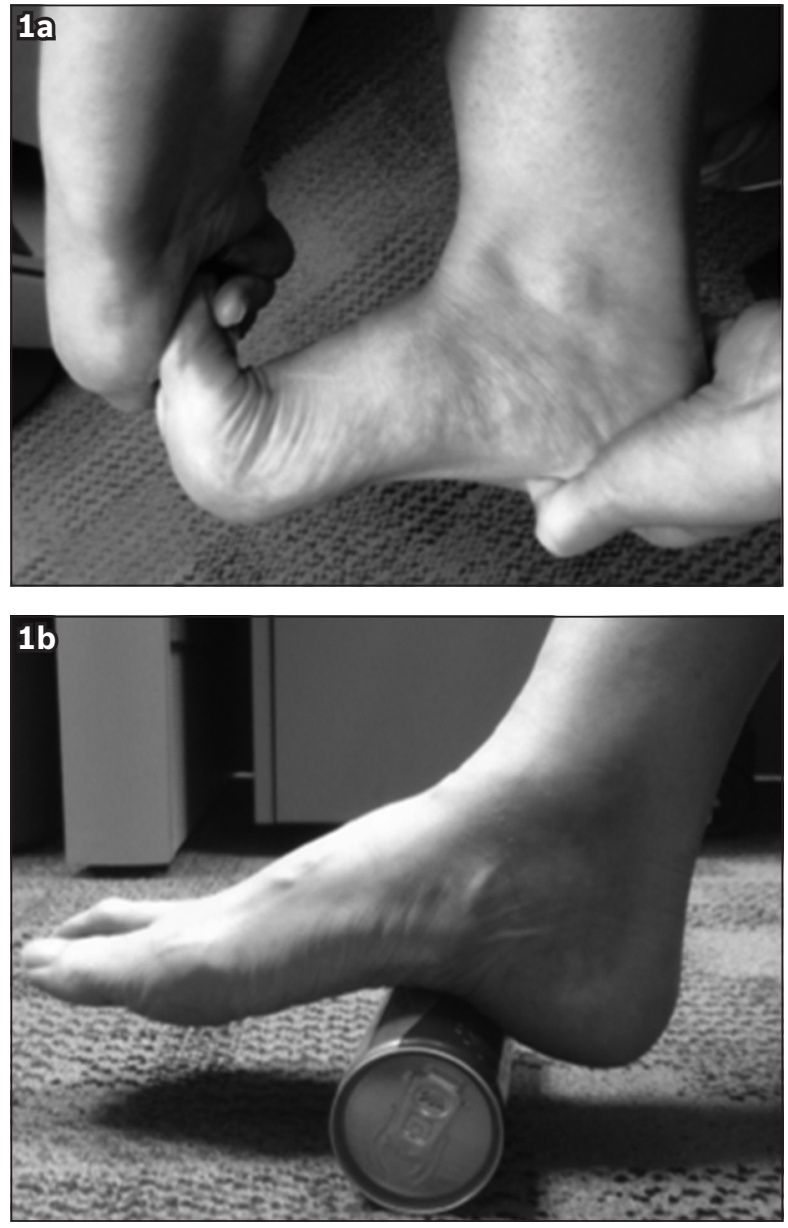

Fig. 1 Photographs show (a) the plantar fascia-specific stretch, and (b) the ice massage method, which involves rolling a frozen can under the foot.

plantar fat pad atrophy and plantar fascia rupture with repeated corticosteroid injections, ${ }^{(17)}$ and thus, repeated injections should be avoided if possible. ${ }^{(18)}$

\section{Platelet-rich plasma injection}

Localised platelet-rich plasma injections have shown much promise and appear to be safe. ${ }^{(19)}$ However, this modality is currently not approved by the Ministry of Health, Singapore, for the treatment of plantar fasciitis.

\section{Focal extracorporeal shockwave therapy}

Patients with recalcitrant plantar fascia pain can be referred to hospitals that offer ultrasonography-guided focal extracorporeal shockwave therapy ( $f \mathbb{E} S W T$ ) as part of their sports medicine service. This treatment has been shown to be efficacious for patients with chronic plantar fasciitis that did not respond well to conservative treatment. ${ }^{(20,21)} \mathbb{E E S W T}$ is a noninvasive procedure that takes about ten minutes per treatment; the patient usually requires two treatments spaced one week apart for optimal efficacy. ${ }^{(22,23)}$

\section{Operative treatment}

If the patient continues to have moderate to severe symptoms that do not respond to nonoperative treatment for more than 6-12 months, referral to an orthopaedic surgeon for operative treatment may be required. 
Albert dropped by your clinic two weeks later to thank you for treating his pain with only the calf and plantar fascia-specific stretch you taught him. He had since revised his health pledge to include a regular exercise programme that combines stationary cycling and a slow jog. He will gradually work toward 150 minutes of moderate exercise a week and will postpone his half marathon pledge for another year.

\section{TAKE HOME MESSAGES}

1. Plantar fasciitis is a common cause of plantar heel pain that can be treated effectively in the outpatient setting.

2. Prolonged standing, decreased range of ankle dorsiflexion, an intense running regime and obesity are all risk factors for plantar fasciitis.

3. A multipronged approach aimed at reducing the load on the plantar fascia is most effective.

4. Activity modification, plantar fascia-specific stretches, calf stretching, orthotics (including cushioned heel cups) and night dorsiflexion splinting can help alleviate symptoms.

5. NSAIDs have limited efficacy for plantar fasciitis.

6. The pain-relieving effects of localised injection of corticosteroids are short-term; its use must also be weighed against the potential side effects of fat pad atrophy and plantar fascia rupture.

7. In moderate to severe cases, ultrasonography-guided $\mathbb{A E S W T}$ is indicated to supplement the supportive measures mentioned above.

8. Changes in a patient's training regime, including reduction of mileage and cross training with low-impact activities such as elliptical machine or stationary cycling, are advisable until the symptoms resolve.

9. Referral for operative treatment may be required in patients who continue to have moderate to severe symptoms that do not respond to nonoperative treatments after 6-12 months.

ABSTRACT Plantar fasciitis is a very common cause of inferior heel pain that can be triggered and aggravated by prolonged standing, walking, running and obesity, among other factors. Treatments are largely noninvasive and efficacious. Supportive treatments, including the plantar fascia-specific stretch, calf stretching, appropriate orthotics and night dorsiflexion splinting, can alleviate plantar fascia pain. While local injections of corticosteroids can help with pain relief, the effects are short-lived and must be weighed against the risk of fat pad atrophy and plantar fascia rupture. Ultrasonographyguided focal extracorporeal shock wave therapy is useful for patients with chronic plantar fasciitis and referrals for this treatment can be made in recalcitrant cases. Activity modification to decrease cyclical repetitive loading of the plantar fascia should be advised during the treatment phase regardless of the chosen treatment modality.

\section{REFERENCES}

1. Riddle DL, Schappert SM. Volume of ambulatory care visits and patterns of care for patients diagnosed with plantar fasciitis: a national study of medical doctors. Foot Ankle Int 2004; 25:303-10.

2. Lemont $\mathrm{H}$, Ammirati KM, Usen N. Plantar fasciitis: a degenerative process (fasciosis) without inflammation. J Am Podiatr Med Assoc 2003; 93:234-7.

3. Beeson P. Plantar fasciopathy: revisiting the risk factors. Foot Ankle Surg 2014; 20:160-5

4. Johal KS, Milner SA. Plantar fasciitis and the calcaneal spur: Fact or fiction? Foot Ankle Surg 2012; 18:39-41.

5. Moroney PJ, O'Neill BJ, Khan-Bhambro K, et al. The conundrum of calcaneal spurs: do they matter? Foot Ankle Spec 2014; 7:95-101.

6. Sabir N, Demirlenk S, Yagci B, Karabulut N, Cubukcu S. Clinical utility of sonography in diagnosing plantar fasciitis. J Ultrasound Med 2005; 24:1041-8.

7. Kane D, Greaney T, Shanahan M, et al. The role of ultrasonography in the diagnosis and management of idiopathic plantar fasciitis. Rheumatology (Oxford) 2001; 40:1002-8.

8. Akfirat M, Sen C, Günes T. Ultrasonographic appearance of the plantar fasciitis. Clin Imaging 2003; 27:353-7.

9. Cheng JW, Tsai WC, Yu TY, Huang KY. Reproducibility of sonographic measurement of thickness and echogenicity of the plantar fascia. J Clin Ultrasound 2012; 40:14-9.

10. Gibbon WW, Long G. Ultrasound of the plantar aponeurosis (fascia). Skeletal Radiol 1999; 28:21-6.

11. Digiovanni BF, Nawoczenski DA, Malay DP, et al. Plantar fascia-specific stretching exercise improves outcomes in patients with chronic plantar fasciitis. A prospective clinical trial with two-year follow-up. J Bone Joint Surg Am 2006; 88:1775-81

12. Batt ME, Tanji JL, Skattum N. Plantar fasciitis: a prospective randomized clinical trial of the tension night splint. Clin J Sport Med 1996; 6:158-62.

13. Landorf KB, Keenan AM, Herbert RD. Effectiveness of foot orthoses to treat plantar fasciitis: a randomized trial. Arch Intern Med 2006; 166:1305-10

14. Baldassin V, Gomes CR, Beraldo PS. Effectiveness of prefabricated and customized foot orthoses made from low-cost foam for noncomplicated plantar fasciitis: a randomized controlled trial. Arch Phys Med Rehabil 2009; 90:701-6.

15. Donley BG, Moore T, Sferra J, Gozdanovic J, Smith R. The efficacy of oral nonsteroidal anti-inflammatory medication (NSAID) in the treatment of plantar fasciitis: a randomized, prospective, placebo-controlled study. Foot Ankle Int 2007; 28:20-3.

16. Crawford F, Atkins D, Young P, Edwards J. Steroid injection for heel pain: evidence of short-term effectiveness. A randomized controlled trial. Rheumatology (Oxford) 1999; 38:974-7.

17. Acevedo JI, Beskin JL. Complications of plantar fascia rupture associated with corticosteroid injection. Foot Ankle Int 1998; 19:91-7.

18. Kennedy JC, Willis RB. The effects of local steroid injections on tendons: a biomechanical and microscopic correlative study. Am J Sports Med 1976; 4:11-21.

19. Wilson JJ, Lee KS, Miller AT, Wang S. Platelet-rich plasma for the treatment of chronic plantar fasciopathy in adults: a case series. Foot Ankle Spec 2014; 7:61-7.

20. Malay DS, Pressman MM, Assili A, et al. Extracorporeal shockwave therapy versus placebo for the treatment of chronic proximal plantar fasciitis: results of a randomized, placebo-controlled, double-blinded, multicenter intervention trial. J Foot Ankle Surg 2006; 45:196-210.

21. Rompe JD, Furia J, Weil L, Maffulli N. Shock wave therapy for chronic plantar fasciopathy. Br Med Bull 2007; 81-82:183-208.

22. Metzner G, Dohnalek C, Aigner E. High-energy Extracorporeal Shock-Wave Therapy (ESWT) for the treatment of chronic plantar fasciitis. Foot Ankle Int 2010; 31:790-6.

23. Ibrahim MI, Donatelli RA, Schmitz C, Hellman MA, Buxbaum F. Chronic plantar fasciitis treated with two sessions of radial extracorporeal shock wave therapy. Foot Ankle Int 2010; 31:391-7. 


\section{SINGAPORE MEDICAL COUNCIL CATEGORY 3B CME PROGRAMME} (Code SMJ 201604A)

1. Plantar fasciitis is the most common cause of plantar heel pain and can be managed effectively in the outpatient setting.

2. Plantar fasciitis is an inflammatory process involving the plantar aponeurosis.

3. Patients with plantar fasciitis often present with medial plantar heel pain that is worse during the first few steps in the morning.

4. Risk factors for plantar fasciitis include obesity, tight calf muscles, prolonged standing, and sudden increase in running volume and/or intensity.

5. Plantar fasciitis can be diagnosed when heel spurs are seen on lateral radiographs of the foot.

6. Ultrasonography results are deemed abnormal when the thickness of the plantar fascia exceeds $4.0 \mathrm{~mm}$.

7. The mainstay of treatment for plantar fasciitis is largely surgical.

8. The plantar fascia-specific stretch has been shown to be efficacious in treating plantar fasciitis.

9. The isolated Achilles tendon stretch is more effective than the plantar fascia-specific stretch in relieving the pain of plantar fasciitis.

10. Plantar fascia-specific stretches should not be done more than three times a day.

11. The use of dorsiflexion night splints can help to improve plantar fascia pain in as little as four weeks.

12. Orthotics can help to alleviate plantar fasciitis but must be custom-fitted, as prefabricated ones are not effective.

13. Nonsteroidal anti-inflammatory drugs have not been shown to be effective in the treatment of plantar fasciitis.

14. A localised injection of steroids can be effective for short-term relief of pain.

15. Multiple localised injections of steroids can be done for the patient who has recurrence of pain after previous injections, as there are no known adverse effects.

16. Ultrasonography-guided focal extracorporeal shockwave therapy ( $f$ ESWT) can be used to treat recalcitrant plantar fasciitis.

17. A single session of ultrasonography-guided $f$ ESWT is enough to treat recalcitrant plantar fasciitis.

18. Activity modification to reduce repetitive impact should be advised.

19. All sporting activities should cease until the patient is completely asymptomatic.

20. Patients should be allowed to gradually increase their amount of repetitive impact activities 4-6 weeks after they become asymptomatic.

\section{Doctor's particulars:}

Name in full

MCR number

Email address

\section{SUBMISSION INSTRUCTIONS:}

(1) Log on at the SMJ website: http://www.sma.org.sg/publications/smjcurrentissue.aspx and select the appropriate set of questions. (2) Provide your name, email address and MCR number. (3) Select your answers and click "Submit".

\section{RESULTS:}

(1) Answers will be published in the SMJ June 2016 issue. (2) The MCR numbers of successful candidates will be posted online at the SMJ website by 30 May 2016. (3) Passing mark is $60 \%$. No mark will be deducted for incorrect answers. (4) The SMJ editorial office will submit the list of successful candidates to the Singapore Medical Council. (5) One CME point is awarded for successful candidates.

Deadline for submission: (April 2016 SMJ 3B CME programme): 12 noon, 23 May 2016. 